\title{
Role of Alcohol in Late-Life Suicide
}

\author{
Frederic C. Blow, Laurie M. Brockmann, and Kristen Lawton Barry
}

\begin{abstract}
Suicide is among the leading causes of death in the United States, ranking 10th to 12th annually, depending on the year. Rates of suicide increase markedly among Americans over age 75, especially among white men. After age 85 , rates are $>5$-fold higher in this group than in the general population. The relationship between alcohol use and later-life suicide is complex and currently ill defined. Substance use disorders, particularly alcohol abuse and dependence, are the second most common category of axis I disorders associated with completed suicide among adults aged 65 and older, following only depression. The co-occurrence of alcohol use disorders and depression heightens suicide risk. Most studies that have evaluated the effects of alcohol in geriatric suicide have focused on older adults who met DSM criteria for abuse and/or dependence. However, the majority of older adults who are experiencing problems related to their alcohol use do not meet alcohol abuse/dependence criteria. Therefore, the role of at-risk and problem alcohol use in geriatric suicide may be underestimated. Drinking among elders elevates suicide risk through interactions with other factors that are more prevalent in this age group, such as depressive symptoms, medical illness, negatively perceived health status, and low social support. This article reviews the literature related to alcohol use and suicide among older adults. Clinical and research recommendations for addressing this problem are also presented.
\end{abstract}

Key Words: Drinking, Elderly, Suicide, Depression, Risk Factors.

$\mathbf{O}$ LDER ADULTS HAVE the highest risk for suicide of any age group in the United States. The causes of elder suicide are multifaceted. Although no predominate factor precipitates or explains geriatric suicide, both depression and alcohol are strongly linked to suicide attempts and completions. Studies of geriatric suicide have been less extensive and rigorous than studies of suicide among other age groups (Conwell and Brent, 1995). Most studies rely on psychological autopsy techniques that collect information from proxy respondents who report for the individual. Compared with finding proxy respondents for younger individuals who commit suicide, it is often more difficult to find respondents who are close to elderly suicide decedents because of illness or death of potential respondents (e.g., spouse, sibling, close friend) and because of the isolation of many older individuals. Despite relatively high rates of suicide among the elderly, low prevalence makes prospective studies of geriatric suicide rare. Therefore, current knowledge regarding geriatric suicide does not clearly distinguish casual risk factors from correlates or fixed markers of risk (Fawcett et al., 1990; Kraemer et al., 1997).

From the University of Michigan, Department of Psychiatry Division of Substance Abuse, Ann Arbor, Michigan.

Received for publication January 21, 2004; accepted February 4, 2004.

Reprint requests: Frederic C. Blow, PhD, Department of Psychiatry, 400 E. Eisenhower Parkway, Suite 2A, Ann Arbor, MI 48108; Fax: 734-761-2617; E-mail: fredblow@umich.edu.

This report presents the findings and conclusions of the authors; it does not necessarily represent the Department of Veterans Affairs or the University of Michigan.

DOI: 10.1097/01.ALC.0000127414.15000.83?
There is a complex relationship between alcohol misuse and later life suicide. Estimates of substance use disorders among elder suicide decedents have been lower than those for younger cohorts (Carney et al., 1994; Conwell et al., 1996; Henriksson et al., 1993). This may reflect, in part, a decline in alcohol use in late life (Myers et al., 1984). However, the role of at-risk and problem alcohol use in geriatric suicide may be underestimated. Potential reasons for this include (1) difficulty of assessing drinking behavior and detecting drinking problems in this population, (2) the increased effect of even light to moderate alcohol use in this age group, and (3) problems with standard criteria for the diagnoses of alcohol abuse and dependence as they are applied to the elderly (Blow, 1998).

The purpose of this article is to explicate the relationships among alcohol misuse, depression, and suicide among older populations and to provide clinical and research recommendations for addressing this problem. Unless otherwise specified, the aged population referred to in this article is 65 years and older.

\section{PREVALENCE AND CHARACTERISTICS OF SUICIDE IN LATER LIFE}

Suicide was the 11th leading cause of death in the United States in 2000, with 10.7 completed suicides for every 100,000 people (Miniño et al., 2002). In that year, older adults had substantially higher suicide rates than the national average, with 15.3 completed suicides per 100,000 individuals. Across the lifespan, men are at greater risk for suicide than women, and whites are at greater risk than 
nonwhites (Conwell and Brent, 1995; Grabbe et al., 1997). Once past mid-life, the risk of suicide increases significantly with age, especially among white men. Men accounted for $84 \%$ of suicides among people aged 65 years and older in 2000 (Miniño et al., 2002). In 1998, white men over 85 committed suicide at nearly six times the national ageadjusted rate (National Center for Health Statistics, 2000).

A combination of factors places the older adult population in a unique and vulnerable position regarding suicide. Compared with younger suicide decedents, elderly suicide decedents are much less likely to have attempted suicide previously (Carney et al., 1994; Parkin and Stengel, 1965). Suicide attempts by older adults are more "successful." Whereas there is one completed suicide for each 25 attempts among all ages, the elderly complete suicide at a ratio of 1 to 4 (McIntosh, 2001; Miniño et al., 2002). Greater use of lethal methods contributes to the higher rate of completed suicides among elders. The proportion of suicides completed by firearms is greater among those 65 and older than for any other age group (McIntosh, 2001; McIntosh and Santos, 1985-1986). In 2000, $72.9 \%$ of suicides that were committed by the elderly involved firearms (Miniño et al., 2002). Older people give fewer suicide "warnings" and have less suicidal ideation (Carney et al., 1994). Social isolation in the elderly makes detection and intervention even more difficult. Because their physical health is poorer overall, older adults are less likely to survive self-inflicted injuries than younger people. In general, older adults who attempt suicide have greater premeditation and seriousness of intent (Conwell, 1994).

Psychiatric illness is a powerful determinant of geriatric suicide risk. Diagnosable major psychiatric illness has been demonstrated through psychological autopsy in $71 \%$ to $>90 \%$ of older suicide decedents (Conwell, 2001; Conwell and Brent, 1995). Depression is the most common psychiatric disorder associated with elder suicide (Barnow and Linden, 2000; Barraclough, 1971; Conwell et al., 1991, 1996; Frierson, 1991; Osgood, 1991; Robins 1981); major depressive disorder is present in one half to two thirds of all older suicide decedents (Conwell and Brent, 1995). A single episode of nonpsychotic, unipolar major depression is the most common psychiatric syndrome of older suicide decedents (Conwell, 2001).

Substance use disorder, particularly alcohol abuse and/or dependence, is the second most common psychiatric disorder associated with completed elder suicide. Estimates based on psychological autopsy studies indicate that a range of 3 to $44 \%$ of elderly suicide decedents had a substance use disorder (Barraclough 1971; Carney et al., 1994; Conwell et al., 1991). Substance use disorders are also associated with elder suicide attempts (Blixen et al., 1997; Frierson, 1991). Most studies of geriatric suicide use DSM-IV (American Psychiatric Association, 1994) criteria or earlier versions of the DSM to assess substance use disorders. As we discuss further below, estimates of the influence of alcohol misuse among older suicide decedents may be low as a result of the use of inappropriate diagnostic criteria to assess alcohol abuse among elders.

\section{ROLE OF ALCOHOL IN LATE-LIFE SUICIDE}

The role of problem drinking in late-life suicide is complex. Mechanisms by which alcohol misuse by elders is associated with suicide include (1) alcohol abuse/dependence as an independent risk factor; (2) alcohol abuse/ dependence or problem drinking interacting with and/or exacerbating a co-occurring psychiatric illness, typically depression; and (3) at-risk or problem drinking exacerbating other suicide risk factors. To understand the potential role of alcohol in suicide, as well as the comorbidity of alcohol and other psychiatric disorders, we begin with an examination of alcohol misuse among the elderly.

\section{Problem Drinking in Older Adulthood}

The misuse and abuse of alcohol is a significant public health problem among the growing population of older adults. The concern for alcohol use is highlighted by the literature demonstrating that not only are alcohol misuse and abuse common in this population but also that problem drinking in late life likely affects a larger proportion of the elderly population than previously thought (Blow, 1998; Williams and Debakey, 1992). Prevalence estimates of problem drinking in older adults derived from community surveys have ranged from 1 to 15\% (Adams et al., 1996; Gurland and Cross, 1982; Robins et al., 1984), and much higher rates (15-58\%) have been estimated among older adults who present at health care settings (Blow and Barry, 1999; Dupree et al., 1984). These rates vary widely depending on method and the definitions of at-risk and problem drinking or alcohol abuse and dependence.

Clarification of terms is essential in a discussion of alcohol problems among older adults. Use that increases the chances that an individual will develop problems and complications is at-risk use. People who are older than 65 years and drink more than seven drinks per week-one per day-are categorized as at-risk users. Although they may not have a current health, social, or emotional problem caused by alcohol, they may be at higher risk to develop family and social problems. If this drinking pattern continues over time, then health and emotional problems are more likely. Older adults who engage in problem use are defined as drinking at a level that has already resulted in adverse medical, psychological, or social consequences. Potential consequences can include injuries, medication interaction problems, and family problems, among others. Some older adults who drink even small amounts of alcohol can experience alcohol-related problems. The terms alcohol abuse and alcohol dependence are used as defined in the DSM-IV (American Psychiatric Association, 1994).

The majority of older adults who are experiencing problems related to their drinking do not meet DSM-IV criteria for alcohol abuse or dependence (Barry et al., 2001; Blow, 
1998). Although alcohol problems are typically thought to occur in people who consume larger quantities and drink frequently, for some older individuals, any alcohol use, particularly when coupled with some psychoactive medications, can present problems.

DSM criteria are widely used and distinguish between abuse and dependence. However, these criteria may not be appropriate for many older adults with substance use problems because people in this age group do not often experience the legal, social, or psychological consequences specified in the criteria. For example, "a failure to fulfill major role obligations at work, home, or school" may be less applicable to retired people with fewer familial and work obligations (Blow, 1998). Furthermore, a tolerance to alcohol may not be as appropriate an indicator of alcoholrelated problems in the elderly as in younger ages. The DSM-IV criterion for tolerance is based on increased consumption over time. This ignores the physiological changes with aging that can lead to physical tolerance to alcohol at low levels of consumption, which clinicians may not identify as meeting the tolerance criterion. In addition, older adults may not experience some of the emotional and social consequences listed in the DSM-IV criteria as a result of isolation from friends, lack of contact with family, retirement, etc.

Compared with younger adults, older individuals have an increased sensitivity to alcohol that increases potential harm. Sensitivity to and tolerance of ethanol are affected by physiologic aging processes (Rosin and Glatt, 1971), as well as by health problems that are more common in older ages (Baker, 1985; Blow, 1998). Alcohol consumption in amounts considered light or moderate for younger adults may have untoward health effects in older people. The age-related decrease in the ratio between lean body mass and fat increases the effective concentration of alcohol and other moodaltering chemicals in the body (Vestal et al., 1977). Liver enzymes that metabolize alcohol and other drugs become less efficient with age. Central nervous system sensitivity to drugs increases with age. Because equivalent drinking produces higher and longer-lasting blood alcohol levels in older compared with younger people, many problems that are common to older people, including chronic illness, poor nutrition, and polypharmacy, may be exacerbated by even small amounts of alcohol (Vestal et al., 1977).

To address at-risk drinking, the National Institute on Alcohol Abuse and Alcoholism (NIAAA) developed separate alcohol consumption guidelines for adults under and over age 65 . These guidelines are based on current rigorous research and, therefore, change as our knowledge changes and expands. Because of the biological, psychological, and social circumstances of aging, older adults pose special challenges for developing appropriate alcohol consumption guidelines. Of particular concern in this age group is the potential interaction of medications and alcohol. For some people, any alcohol use coupled with the use of specific over-the-counter or prescription medications can be prob- lematic. Hence, recommended limits on alcohol consumption for older adults are generally lower than those for adults under age 65 . It is important to understand both the impact of even low to moderate levels of alcohol use and the problems associated with applying DSM criteria to older adult alcohol problems (see Blow, 1998).

Both the NIAAA and the Center for Substance Abuse Treatment Treatment Improvement Protocol on older adults recommend that people age 65 and older consume no more than one standard drink per day or seven standard drinks per week (Blow, 1998; Dufour and Fuller, 1995). These drinking guidelines for older adults are consistent with research data evaluating the relationship between consumption and alcoholrelated problems in this age group (Chermack et al., 1996). The recommendations are also consistent with the current evidence on the beneficial health effects of drinking (Broe et al., 1998; Doll et al., 1994; Klatsky et al., 1990; Poikolainen, 1991; Thun et al., 1997)

Conflicting evidence remains, however, regarding the positive and negative aspects of alcohol consumption. Confounding the issue of the one drink per day recommended limit is the potential benefit of moderate alcohol consumption, especially with regard to cardiovascular disease (Scherr et al., 1992; Thun et al., 1997). There is growing evidence that among otherwise healthy adults, especially middle-aged adults, moderate alcohol use may reduce cardiovascular disease, may reduce the risk of some dementing illnesses, and may have benefits in reducing cancer risk (Boffetta and Garfinkel, 1990; Broe et al., 1998; deLabry et al., 1992; Orgogozo et al., 1997). Alcohol in moderate amounts may also improve self-esteem and provide relaxation. Alcohol is often consumed socially and has been assumed to help reduce stress, at least temporarily. Little research in these areas, however, has been conducted specifically with older adults.

The mixed reports regarding the detrimental effects and potential benefits of alcohol use may confuse clinicians who debate whether to recommend reduction in consumption for older adults who do not meet criteria for abuse/dependence and, perhaps, even for those who do. Conigliaro et al. (1998) surveyed patients in all age groups who were identified as "problem drinkers" and recently had a primary care visit. The majority of the patients remembered having a discussion with their doctor about drinking, but only half remembered being advised to reduce consumption. For older adults who are more susceptible to both the physiologic and the psychosocial effects of substance use, erring on the side of caution with nonconfrontational messages and follow-up is generally the most practical and effective approach.

\section{Alcohol and Suicide in Later Life}

Alcohol Use/Misuse. Alcohol use and misuse are more prevalent among the suicidal than the nonsuicidal elderly. However, the literature explicating the relationships be- 
tween alcohol and elder suicide is limited, and because of the variation in study methods, the role of alcohol use and misuse in geriatric suicide has been found to vary across studies. Using a case-control study nested within a large ongoing cohort study of residents of a Southern California retirement community, Ross et al. (1990) compared elder suicide decedents with age-matched control subjects and found greater alcohol use among elders who completed suicide. In contrast, a recent prospective community-based study found that older suicide decedents did not have greater alcohol use than control subjects (Turvey et al., 2002). However, the suicide decedents in this study had substantially poorer perceived health, poorer sleep quality, and other differences that were not controlled in evaluating differences in alcohol use.

A retrospective study compared deaths by suicide, injury, and natural causes in a nationally representative sample of 10,134 deaths among the elderly in 1986 (Grabbe et al., 1997). Using adjusted logistic regression analyses, suicides were compared with other causes of death. Moderate (one to two drinks per day) and heavier (three or more drinks per day) alcohol users were each significantly more likely than nondrinkers to die by suicide.

Use at the Time of Suicide Studies have evaluated the portion of older suicide decedents who had consumed alcohol immediately before the suicide event. A study of medical examiner toxicology reports on older suicide decedents found that $14.8 \%$ of 64 - to 73 -year-olds and $5.8 \%$ of those aged 74 and older had alcohol present in the blood stream at autopsy (Conwell et al., 1990). In a study of elder suicide attempts, $24.5 \%$ of patients aged 60 to 69 and $13 \%$ of those patients aged 70 to 79 had consumed alcohol before the attempt (Frierson, 1991).

Suicidal Ideation. Studies of suicidal ideation in the elderly have not indicated a strong relationship between ideation and alcohol use, alcohol problems, or alcohol abuse/dependence unless comorbid depression was also present (Bartels et al., 2002; Callahan et al., 1996). However, Bartels et al. (2002) did find indications of a complex relationship between the severity of the alcohol use disorder and suicidal ideation among older adults.

The mixed results in the literature reflect the varying study methods, but they also reflect the serious and complex relationship between alcohol use and suicide in older adults. Nondependent alcohol use/misuse without a cooccurring depression or other significant risk factor may not increase suicide risk among older people. Research in this area is of critical importance because low to moderate alcohol use among some elderly may, in fact, be an indication of better health (Blow et al., 2000a,b). For others, however, even low alcohol use may indicate at-risk or problem drinking behavior that could aggravate other suicide-related risk factors, including health problems and depression.

\section{Comorbid Alcohol Abuse/Dependence and Depression}

There is a small body of literature addressing comorbid alcohol abuse/dependence and affective disorders in older adults. Research has shown a strong association between depression and alcohol use disorders across age cohorts; this linkage continues in later life. In a national study of people aged 65 and older, $13.3 \%$ of those with lifetime major depression also met criteria for a lifetime alcohol use disorder, whereas only $4.5 \%$ of those without a history of depression had a lifetime alcohol use disorder (Grant and Harford, 1995).

Studies of clinical populations have demonstrated the prevalence of comorbid affective disorders and alcohol abuse among older adults. Blixen et al. (1997) found 38\% of older adults who were admitted to a freestanding psychiatric hospital had both a substance abuse disorder and another psychiatric disorder, primarily depression. Speer (1990) found that $48 \%$ of older psychiatric inpatients had received mood disorder plus alcohol abuse diagnoses. Blow et al. (1992b) found major depression among 8 to $12 \%$ of older alcoholics who sought outpatient treatment in the Veterans Affairs mental health care system in 1986 and dysthymic disorder among 5 to $8 \%$ of the same population.

At-risk and problem drinking among the elderly is likely to exacerbate existing depressive disorders (Atkinson, 1999; Coyne and Schwenk, 1997). Associations have been shown between current alcohol consumption and depression scores on the Center for Epidemiologic Studies-Depression scale in people aged 65 and older (Graham and Schmidt, 1999) and past alcohol consumption and current depressive disorders in older men (Saunders et al., 1991).

Recent research that included adults of all ages found that both alcohol dependence and major depression posed a significant risk for the development of the other disorder (Gilman and Abraham, 2001). Other research among adult subjects indicated that when comorbid depression and alcohol use disorders are present, both disorders tend to be more severe than when either one occurs alone (Grant et al., 1996; Hanna and Grant, 1997). Comorbidity in these patients can be more difficult to diagnose and treat because each illness may complicate the other (McKenna and Ross, 1994). Atkinson (1999) provided an excellent discussion of research regarding the complex connections between latelife depression and alcohol use disorders.

Subsyndromal depression may be aggravated by drinking, leading to full-blown depressive disorder. This is exemplified in grief-associated depressive symptoms or latelife adjustment disorders with depressed mood that may increase to levels consistent with major depressive disorder (Atkinson, 1999). For example, a recent widow/widower may use alcohol in an attempt to mitigate depression. Reinforcing positive feelings associated with drinking may lead to continued alcohol use, which may increase depressive symptoms-both those associated with loss of the partner and those brought on by alcohol use itself (e.g., 
health-related difficulties, rejection by others as a result of drinking, financial strain). The resultant cycle may lead to a major depression episode.

Among all ages, the co-occurrence of diagnosed alcohol abuse and mood disorders is associated with greater suicide risk than either diagnosis alone. Waller et al. (1999) in a study of veterans aged 23 to 78 found that those with unipolar or bipolar affective disorders and a concurrent alcohol use disorder consistently had increased suicidality risk. Among patients who presented to a psychiatric facility for initial evaluation, compared with patients with either major depression or alcohol dependence alone, Cornelius et al. (1995) found that depressed alcoholics "suffer an additive or synergistic effect of two separate disorders, resulting in a disproportionately high level of acute suicidality upon initial psychiatric evaluation."

Elder-specific research has provided support for the association of greater suicide risk among those with cooccurring alcohol abuse with another psychiatric illness. Following up on elders who were discharged from a psychiatric hospital, Blixen et al. (1997) found that psychiatric readmission for a suicide attempt was significantly more common among those with a previous psychiatric diagnosis and comorbid substance abuse diagnoses (17.7\%) than those with a psychiatric diagnosis without co-occurring substance abuse $(3.3 \%)$. There were no significant differences between the two groups in self-reported suicidal ideation before admission.

\section{PHYSICAL AND EMOTIONAL RISK FACTORS IN GERIATRIC SUICIDE}

There is little research evaluating mechanisms that relate elder drinking to suicide risk. Several prominent risk factors for elder suicide, however, are affected by at-risk and problem drinking.

Medical illness and general poor health are major contributors to geriatric depression (Depression Guideline Panel, 1993). Drinking that aggravates health problems increases the likelihood of depressive symptoms and potential suicide. Late-life drinking may also have an impact on other suicide risk factors, including psychiatric problems, negatively perceived health status, treatment noncompliance, and poor sleep quality (see Brown et al., 2001; Conwell, 2001; Conwell et al., 1990, 1991; Lavretsky et al., 2002; Pearson and Brown, 2000; Turvey et al., 2002 for suicide risk factors). Drinking also affects levels of pain and vitality in older adults (Blow et al., 2000a,b). At-risk drinking may have other significant affects that lead to harmful drug interactions, injury, memory problems, liver disease, cardiovascular disease, cognitive changes, and sleep problems (Barry, 1997; Fleming and Barry, 1992; Gambert and Katsoyannis, 1995; Liberto et al., 1992; Wetle, 1997).

Late-life drinking influences psychosocial risk factors for elder suicide. At-risk or problem drinking can place strains on existing relationships and threaten social support net- works. For elders, social isolation, poor social support, and a lack of relatives or friends in whom to confide all increase risks for depression and suicide in later life (Conwell, 2001; Conwell et al., 1990, 1991; Turvey et al., 2002). Alcohol misuse in older drinkers has been shown to impair both emotional and social functioning (Blow et al., 2000a,b). Risk factors such as a negative or depressed mental outlook, hopelessness, a lack of reason for living, poor impulse control, and recent stressful life events have also been correlated with suicide among elders (Brown et al., 2001; Pearson and Brown, 2000; Ross et al., 1990; Turvey et al., 2002). When drinking has been used as a life-long coping strategy, older individuals who are faced with major life changes, loss and grief, and financial stress can develop dangerous patterns of misuse that erode social supports and internal coping processes, leaving them more vulnerable to depression and, potentially, suicide.

\section{FUTURE TRENDS AMONG OLDER DRINKERS}

At all ages, the large post-World War II "Baby Boom" cohort has had substantially higher suicide rates than preceding generations at their ages (McIntosh, 1992). Older people are the fastest growing segment of the population; this demographic shift alone is projected to double the number of late-life suicides committed by the year 2030 (Haas and Hendin, 1983). Experts' predictions vary, however, regarding the effect of aging of the Baby Boom generation and its expected impact on suicide rates, potentially moving them in either direction (see Conwell, 2001).

Drinking patterns over the life course and among age cohorts also vary significantly, with the Baby Boom generation drinking greater quantities and more frequently than earlier cohorts (Blow et al., 2002a; Korper and Council, 2002). Grant (1997) pointed out that the social structure, attitudes, and expectancies of each cohort affect the extent to which members of that cohort engage in heavier drinking and experience more alcohol-related problems.

The last century has seen a shift toward younger initiation of alcohol use and increased alcohol dependence among drinkers. Grant (1997) also reported convergence in the rates of substance abuse/dependence between men and women as a result of increased consumption by women. Recent studies also indicate substantial changes in patterns of substance use and abuse in different birth cohorts, especially among those born after World War II (Johnstone et al., 1996; Korper and Council, 2002; NIAAA, 1998; Nelson et al., 1998). Analyses of data from a large national survey, the National Longitudinal Alcohol Epidemiologic Survey, indicate that the Baby Boom cohort has higher rates of alcohol and other drug abuse/dependence than expected based on previous cohorts at midlife (Blow et al., $2002 b$ ). This combination of factors-the increasing number of older adults who use alcohol, the risks of comorbid alcohol misuse and depression, and the high rates of suicide 
among the elderly—should make this a priority concern for clinical practice and research.

\section{CLINICAL RECOMMENDATIONS}

The health care delivery system remains one of the most efficient and effective venues in which to detect this array of problems and improve the quality of life for many older adults. American and British studies have shown that between 43 and $76 \%$ of elder suicide decedents saw a primary care provider within 30 days before the suicide (Barraclough, 1971; Carney et al., 1994; Cattell and Jolley, 1995; Conwell, 1994; Miller, 1976). For example, in one study, 70 to $75 \%$ of elderly suicide decedents saw their primary care provider in the month before suicide-39\% in the last week and $20 \%$ on the same day (Conwell, 1994).

Lack of controlled studies limits information on specific risk factors and hinders the development of effective intervention strategies targeted at elder suicide prevention (Conwell et al., 2002; Pearson and Brown, 2000). Pearson and Brown (2000) suggested that, in the absence of proven interventions to reduce geriatric suicidal behaviors, the best approach currently available is to improve detection and treatment of later-life depression. Identification and treatment of at-risk or problem alcohol use among elders offers additional potential for preventing geriatric suicide. Availability of useful screening tools, assessment protocols, and treatments for late-life alcohol misuse and depression is increasing, as is the understanding of existing barriers to timely recognition and appropriate treatment (Blow, 1998; Pearson and Brown, 2000).

Many clinicians may need training aimed at effectively assessing problem use of alcohol and other psychoactive prescription drugs, depression, and suicide risk among older adults. Health care delivery occurs in a fast-paced environment with many competing demands on clinicians. Providers are less likely to recognize and treat alcohol misuse (Blow, 1998) or depression (Depression Guideline Panel, 1993; Perez-Stable et al., 1990; Schulberg and McClelland, 1987) in older compared with younger individuals. Because many older adults confront multiple challenges, including social isolation, loss and grief, economic difficulties, and physical illnesses, health care professionals may assume that symptoms result from these difficulties and therefore miss symptoms of depression and alcohol misuse.

Improved diagnosis may result from incorporating questions about alcohol misuse, depressive symptoms, and suicidality into standard health screening instruments to be given yearly and/or after significant life events (e.g., retirement, major illness, loss of any family members and/or friends). Several short screening instruments have high levels of sensitivity and specificity to detect problem drinking in older patients (Blow et al., 1992a; Fleming et al., 1999): the Short Michigan Alcoholism Screening TestGeriatric version (sensitivity $=0.89$, specificity $=0.72$ )
(Blow et al., 1992a) and the Health Screening Survey, which includes questions about alcohol use, nutrition, exercise, and smoking (sensitivity $=0.78$, specificity $=0.71$ in a primary care sample; sensitivity $=0.96$, specificity $=0.75$ in a treatment sample) (Fleming and Barry, 1991; Fleming et al., 1999). Efficient and valid depression screening measures also exist for the elderly (Schade et al., 1998).

Training and organizational support for brief interventions may increase the use of existing evidence-based methods to intervene rapidly and effectively with patients who are misusing alcohol. Research has shown that brief interventions for hazardous drinking are effective in reducing drinking levels across a variety of health care settings (Babor and Grant, 1992; Chick et al., 1985; Fleming et al., 1997; Harris and Miller, 1990; Wallace et al., 1988). Such interventions include personalized feedback by a health care professional on the basis of the patients' responses to screening questions and generic messages with advice to cut back or stop drinking. The majority of older adults who are at-risk drinkers may benefit from brief structured alcohol interventions that can be incorporated into primary care settings (Bien et al., 1993; Fleming et al., 1999).

Alcohol research has led to the development of screening, intervention, and referral techniques that are both clinically and cost-effective. Remaining challenges include increasing coverage by Medicare and private health insurance plans to broaden access to care. However, trends in the characteristics of the evolving elderly population, as described above, underscore the importance of using these brief cost-effective techniques with older at-risk and problem drinkers.

\section{RESEARCH DIRECTIONS}

Risk profiles for geriatric suicide that include specific risk factors associated with problem drinking and depression and their interactions should be developed and tested among the elderly. Understanding the interactions among biological, psychological, and social factors in the aging process will enhance the development and evaluation of treatment and prevention models for geriatric alcohol misuse, depression, and, ultimately, suicide. Evaluation of the impact of various levels of alcohol use/problems on the risk for depression and suicidal behavior is critical in expanding our understanding of the role of alcohol in geriatric suicide. Finally, brief intervention strategies should be developed for use in health care settings, including primary care settings, emergency departments, assisted living facilities, and nursing homes. The early identification and secondary prevention of alcohol problems and their relationship to suicide risk in later life are major areas in which research and clinical strides can be made (Centers for Disease Control and Prevention, 2002; Dufour et al., 1992). 


\section{REFERENCES}

Adams W, Barry KL, Fleming MF (1996) Screening for alcohol use in older primary care patients. JAMA 279:1964-1967.

American Psychiatric Association (1994) DSM-IV: Diagnostic and Statistical Manual of Mental Disorders. 4th ed. American Psychiatric Association, Washington, DC.

Atkinson RL (1999) Depression, alcoholism and ageing: a brief review. Int J Geriatr Psychiatry 14:905-910.

Babor TF, Grant M (1992) Project on Identification and Management of Alcohol-Related Problems. Report on Phase II: A Randomized Clinical Trial of Brief Interventions in Primary Health Care. World Health Organization, Geneva.

Baker SL (1985) Substance abuse disorders in aging veterans, in Alcohol, Drug Addiction and Aging (Gottheil E, Druley RA, Skiloday TE, Waxman H eds), pp 303-311. Charles C. Thomas, Springfield, IL.

Barnow S, Linden M (2000) Epidemiology and psychiatric morbidity of suicidal ideation among the elderly. Crisis 21:171-180.

Barraclough BM (1971) Suicide in the elderly. Br J Psychiatry (Suppl) 6:87-97.

Barry KL (1997) Alcohol and drug abuse, in Fundamentals of Clinical Practice: A Textbook on the Patient, Doctor, and Society (Mengel M, Holloman W eds). Plenum Medical Book Company, New York.

Barry KL, Oslin DW, Blow FC (2001) Alcohol Problems in Older Adults: Prevention and Management. Springer, New York.

Bartels SJ, Coakley E, Oxman TE, Constantino G, Oslin D, Chen H, Zubritsky C, Cheal K, Durai UN, Gallo JJ, Llorente M, Sanchez H (2002) Suicidal and death ideation in older primary care patients with depression, anxiety, and at-risk alcohol use. Am J Geriatr Psychiatry 10:417-427.

Bien TH, Miller WR, Tonigan JS (1993) Brief interventions for alcohol problems: a review. Addiction 88:315-336.

Blixen CE, McDougall GJ, Suen L (1997) Dual diagnosis in elders discharged from a psychiatric hospital. Int J Geriatr Psychiatry 12:307-313.

Blow FC (1998) Substance Abuse Among Older Adults. Treatment Improvement Protocol (TIP) Series No 26. U.S. Department of Health and Human Services, Public Health Service, Substance Abuse and Mental Health Services Administration, Center for Substance Abuse Treatment, Rockville, MD.

Blow FC, Barry KL (1999) Advances in alcohol screening and brief intervention with older adults, in Advances in Medical Psychotherapy, 1999-2000 Volume 10 (Lichtenberg PA ed), pp 107-124. Kendall Hunt, Dubuque, IA.

Blow FC, Barry KL, Fuller BE, Booth BM (2002a) Analysis of the National Health and Nutrition Examination Survey (NHANES): longitudinal analysis of drinking over the Life Span, in Substance Use by Older Adults: Estimates of Future Impact on the Treatment System. Department of Health and Human Services, Substance Abuse and Mental Health Services Administration, Office of Applied Studies, Rockville, MD.

Blow FC, Barry KL, Welsh DE, Booth BM (2002b) National Longitudinal Alcohol Epidemiologic Survey (NLAES) Alcohol and Drug Use Across Age Groups, in Substance Use by Older Adults: Estimates of Future Impact on the Treatment System. Department of Health and Human Services, Substance Abuse and Mental Health Services Administration, Office of Applied Studies, Rockville, MD.

Blow FC, Brower KJ, Schulenberg JE, Demo-Dananberg LM, Young JP, Beresford TP (1992a) The Michigan Alcoholism Screening Test-Geriatric Version (MAST-G): a new elderly-specific screening instrument (abstract). Alcohol Clin Exp Res 16:372.

Blow FC, Cook CA, Booth BM, Falcon SP, Friedman MJ (1992b) Agerelated psychiatric comorbidities and level of functioning in alcoholic veterans seeking outpatient treatment. Hosp Community Psychiatry 43:990-995.

Blow FC, Walton MA, Chermack ST, Barry KL, Coyne JC, Gomberg ESL, Mudd SA (2000a) The relationship between alcohol problems and health functioning of older adults in primary care settings. J Am Geriatr Soc 48:769-774.
Blow FC, Walton MA, Chermack ST, Mudd SA, Brower KJ, Comstock MA (2000b) Treatment outcome for elderly alcoholics following elderspecific inpatient treatment. J Subst Abuse Treat 19:67-75.

Boffetta P, Garfinkel L (1990) Alcohol drinking and mortality among men enrolled in an American Cancer Society prospective study. Epidemiology 1:342-348.

Broe GA, Creasey H, Jorm AF, Bennett HP, Casey B, Waite LM, Grayson DA, Cullen J (1998) Health habits and risk of cognitive impairment and dementia. Aust N Z J Public Health 22:621-623.

Brown GK, Bruce ML, Pearson JL (2001) High risk management guidelines for elderly suicidal patients in primary care settings. Int J Geriatr Psychiatry 16:593-601.

Callahan CM, Hendrie HC, Nienaber NA, Tierney WM (1996) Suicidal ideation among older primary care patients. J Am Geriatr Soc 44:12051209.

Carney SS, Rich CL, Burke PA, Fowler RC (1994) Suicide over 60: the San Diego study. J Am Geriatr Soc 42:174-180.

Cattell G, Jolley DJ (1995) One hundred cases of suicide in elderly people. Br J Psychiatry 166:451-457.

Centers for Disease Control and Prevention (2002) Web-based Injury Statistics Query and Reporting System (WISQARS). National Center for Injury Prevention and Control, Centers for Disease Control and Prevention. Available: www.cdc.gov/ncipc/wisqars.

Chermack ST, Blow FC, Hill EM, Mudd SA (1996) The relationship between alcohol symptoms and consumption among older drinkers. Alcohol Clin Exp Res 20:1153-1158.

Chick J, Lloyd G, Crombie E (1985) Counseling problem drinkers in medical wards: a controlled study. BMJ 290:965-967.

Conigliaro J, Lofgren RP, Hanusa BH (1998) Screening for problem drinking: impact on physician behavior and patient drinking habits. J Gen Intern Med 13:251-256.

Conwell Y (1994) Suicide in elderly patients, in Diagnosis and Treatment of Depression in Late Life (Schneider LS, Reynolds CF III, Lebowitz BD, Friedhoff AJ eds), pp 397-418. American Psychiatric Press, Washington, DC.

Conwell Y (2001) Suicide in later life: a review and recommendations for prevention. Suicide Life Threat Behav (Suppl) 31:32-47.

Conwell Y, Brent D (1995) Suicide and aging I: patterns of psychiatric diagnosis. Int Psychogeriatr 7:149-164.

Conwell Y, Duberstein PR, Caine ED (2002) Risk factors for suicide in later life. Biol Psychiatry 52:193-204.

Conwell Y, Duberstein PR, Cox C, Herrmann JH, Forbes NT, Caine ED (1996) Relationships of age and axis I diagnoses in victims of completed suicide: a psychological autopsy study. Am J Psychiatry 153:1001-1008.

Conwell Y, Olsen K, Caine ED, Flannery C (1991) Suicide in later life: psychological autopsy findings. Int Psychogeriatr 3:59-66.

Conwell Y, Rotenberg M, Caine ED (1990) Completed suicide at age 50 and over. J Am Geriatr Soc 38:640-644.

Cornelius JR, Salloum IM, Mezzich J, Cornelius MD, Fabrega H Jr, Ehler JG, Ulrich RF, Thase ME, Mann JJ (1995) Disproportionate suicidality in patients with comorbid major depression and alcoholism. Am J Psychiatry 152:358-364.

Coyne JC, Schwenk TL (1997) The relationship of distress to mood disturbance in primary care and psychiatric populations. J Consult Clin Psychol 65:161-168.

deLabry LO, Glynn RJ, Levenson MR, Hermos JA, Lacastro JS, Vokonas PS (1992) Alcohol consumption and mortality in an American male population: recovering the U-shaped curve-findings from a normative aging study. J Stud Alcohol 53:25-32.

Depression Guideline Panel (1993) Depression in Primary Care. Volume 1: Detection and Diagnosis. Clinical Practice Guideline, Number 5. Agency for Health Care Policy and Research, Rockville, MD (AHCPR Publication No. 93-0550).

Doll R, Peto R, Hall E, Wheatley K, Gray R (1994) Mortality in relation to consumption of alcohol: 13 years' observations on male British doctors. Br Med J 309:911-918. 
Dufour M, Fuller RK (1995) Alcohol in the elderly. Annu Rev Med 46:123-132.

Dufour MC, Archer L, Gordis E (1992) Alcohol and the elderly. Clin Geriatr Med 8:127-141.

Dupree LW, Broskowski H, Schonfeld L (1984) The gerontology alcohol project: a behavioral treatment program for elderly alcohol abusers. Gerontologist 24:510-516.

Fawcett J, Scheftner WA, Fogg L, Clark DC, Young MA, Hedeker D, Gibbons R (1990) Time-related predictors of suicide in major affective disorder. Am J Psychiatry 147:1189-1194.

Fleming MF, Barry KL (1991) A three-sample test of a masked alcohol screening questionnaire. Alcohol Alcohol 26:81-91.

Fleming MF, Barry KL (1992) Addictive Disorders. Mosby-Year Book, St. Louis.

Fleming MF, Barry KL, Manwell LB, Johnson K, London R (1997) Brief physician advice for problem alcohol drinkers: a randomized controlled trial in community-based primary care practices. Alcohol Alcohol 277: $1039-1045$.

Fleming MF, Manwell LB, Barry KL, Adams W, Stauffacher EA (1999) Brief physician advice for alcohol problems in older adults: a randomized community-based trial. J Fam Pract 48:378-384.

Frierson RL (1991) Suicide attempts by the old and the very old. Arch Intern Med 151:141-145.

Gambert SR, Katsoyannis KK (1995) Alcohol-related medical disorders of older heavy drinkers, in Alcohol and Aging (Beresford T, Gomberg ESL eds), pp 70-81. Oxford University Press, New York.

Gilman SE, Abraham HD (2001) A longitudinal study of the order of onset of alcohol dependence and major depression. Drug Alcohol Depend 63:277-286.

Grabbe L, Demi A, Camann MA, Potter L (1997) The health status of elderly persons in the last year of life: a comparison of deaths by suicide, injury and natural causes. Am J Public Health 87:434-437.

Graham K, Schmidt G (1999) Alcohol use and psychosocial well-being among older adults. J Stud Alcohol 60:345-351.

Grant BF (1997) Prevalence and correlates of alcohol use and DSM-IV alcohol dependence in the United States: results of the National Longitudinal Alcohol Epidemiologic Survey. J Stud Alcohol 58:464-473.

Grant BF, Harford TC (1995) Comorbidity between DSM-IV alcohol use disorders and major depression: results of a national survey. Drug Alcohol Depend 39:197-206.

Grant BF, Hasin DS, Dawson DA (1996) The relationship between DSM-IV alcohol use disorders and DSM-IV major depression: examination of the primary-secondary distinction in a general population sample. J Affect Disord 38:113-128.

Gurland BJ, Cross PS (1982) Epidemiology of psychopathology in old age: some implications for clinical services. Psychiatr Clin North Am 5:1126.

Haas AP, Hendin H (1983) Suicide among older people: projections for the future. Suicide Life Threat Behav 13:147-154.

Hanna EZ, Grant BF (1997) Gender differences in DSM-IV alcohol use disorders and major depression as distributed in the general population: clinical implications. Compr Psychiatr 38:202-212.

Harris KB, Miller WR (1990) Behavioral self-control training for problem drinkers: components of efficacy. Psychol Addict Behav 4:82-90.

Henriksson MM, Aro HM, Marttunen MJ, Heikkinen ME, Isometsa ET, Kuoppasalmi KI, Lonnqvist JK (1993) Mental disorders and comorbidity in suicide. Am J Psychiatry 150:935-940.

Johnstone BM, Leino EV, Ager CR, Ferrer H, Fillmore KM (1996) Determinants of life-course variation in the frequency of alcohol consumption: meta-analysis of studies from the collaborative alcoholrelated longitudinal project. J Stud Alcohol 57:494-506.

Klatsky AL, Armstrong M, Friedman GD (1990) Risk of cardiovascular mortality in alcohol drinkers, ex-drinkers and nondrinkers. Am J Cardiol 66:1237-1242.

Korper SP, Council CL (2002) Substance Use by Older Adults: Estimates of Future Impact on the Treatment System. Substance Abuse and Mental
Health Services Administration, Office of Applied Studies, Rockville, MD (DHHS Publication No SMA03-3763, Analytic Series A-21).

Kraemer HC, Kazdin AE, Offord DR, Kessler RC, Jensen PS, Kupfer DJ (1997) Coming to terms with the terms of risk. Arch Gen Psychiatry 54:337-343.

Lavretsky H, Bastani R, Gould R, Huang D, Llorente M, Maxwell A, Jarvik L, The UPBEAT Collaborative Group (2002) Predictors of two-year mortality in a prospective "UPBEAT" study of elderly veterans with comorbid medical and psychiatric symptoms. Am J Geriatr Psychiatry 10:458-468.

Liberto JG, Oslin DW, Ruskin PE (1992) Alcoholism in older persons: a review of the literature. Hosp Community Psychiatry 43:975-984.

McIntosh JL (1992) Epidemiology of suicide in the elderly. Suicide Life Threat Behav 22:15-35.

McIntosh JL (2001) USA suicide (1999) official final data. American Association of Suicidology. Available: www.iusb.edu/ jmcintos/ USA99Summary.htm.

McIntosh JL, Santos JF (1985-1986) Methods of suicide by age: sex and race differences among the young and old. Int J Aging Hum Dev 22:123-139.

McKenna C, Ross C (1994) Diagnostic conundrums in substance abusers with psychiatric symptoms: variables suggestive of dual diagnosis. Am J Drug Alcohol Abuse 20:397-412.

Miller M (1976) Geriatric suicide: the Arizona study. Gerontologist 18: 488-495.

Miniño AM, Arias E, Kochanek KD, Murphy SL, Smith BL (2002) Deaths: final data for 2000. Natl Vital Stat Rep 50:1-19.

Myers JK, Weissman MM, Tischler GL, Holzer CE 3rd, Leaf PJ, Orvaschel H, Anthony JC, Boyd JH, Burke JD Jr, Kramer M, et al. (1984) Six-month prevalence of psychiatric disorders in three communities, 1980-1992. Arch Gen Psychiatry 41:959-967.

National Center for Health Statistics (2000) National Center for Health Statistics. Available: www.cdc.gov/nchs/datawh/statab/unpubd/mortabs/ gmwk291.htm.

National Institute on Alcohol Abuse and Alcoholism (1998) Drinking in the United States: Main Findings From the 1992 National Longitudinal Alcohol Epidemiologic Survey (NLAES): U.S. Alcohol Epidemiologic Data Reference Manual Volume 6. 1st ed. U.S. Government Printing Office, Washington, DC (NIH Publication No. 99-3519).

Nelson CB, Heath AC, Kessler RC (1998) Temporal progression of alcohol dependence symptoms in the U.S. household population: results from the National Comorbidity Survey. J Consult Clin Psychol 66:474483.

Orgogozo JM, Streim JE, Parmelee P, Boyce AA, Katz IR (1997) Wine consumption and dementia in the elderly: a prospective community study in the Bordeaux area. Rev Neurol (Paris) 153:185-192.

Osgood NJ (1991) Psychological factors in late-life suicide. Crisis 12:1824.

Parkin D, Stengel E (1965) Incidence of suicidal attempts in an urban community. Br Med J 2:133.

Pearson JL, Brown GK (2000) Suicide prevention in later life: directions for science and practice. Clin Psychol Rev 20:685-705.

Perez-Stable EJ, Miranda J, Muñoz R, Ying Y (1990) Depression in medical outpatients: underrecognition and misdiagnosis. Arch Intern Med 150:1083-1088.

Poikolainen K (1991) Epidemiologic assessment of population risks and benefits of alcohol use. Alcohol Alcohol Suppl 1:27-34.

Robins E (1981) The Final Months: A Study of the Lives of 134 Persons Who Committed Suicide. Oxford University Press, New York.

Robins LN, Helzer JE, Weissman MM, Orvascel H, Gruenberg E, Burke JD, Reigler DA (1984) Lifetime prevalence of specific psychiatric disorders in three sites. Arch Gen Med 41:949-958.

Rosin AJ, Glatt MM (1971) Alcohol excess in the elderly. Q J Stud Alcohol 32:53-59.

Ross R, Bernstein L, Trent L, Henderson B, Paganini-Hill A (1990) A prospective study of risk factors for traumatic deaths in a retirement community. Prev Med 19:323-334. 
Saunders PA, Copeland JR, Dewey ME, Davidson IA, McWillim C, Sharma V, Sullivan C (1991) Heavy drinking as a risk factor for depression and dementia in elderly men. Br J Psychiatry 159:213-216.

Schade CP, Jones ER, Wittlin BJ (1998) A ten-year review of the validity and clinical utility of depression screening. Psychiatr Serv 49:55-61.

Scherr PA, LaCroix AZ, Wallace RB, Berkman L, Curb JD, CoroniHuntley J, Evans DA, Hennekens CH (1992) Light to moderate alcohol consumption and mortality in the elderly. J Am Geriatr Soc 40:651-657.

Schulberg HC, McClelland M (1987) A conceptual model for educating primary care providers in the diagnosis and treatment of depression. Gen Hosp Psychiatry 9:1-10.

Speer DC (1990) Comorbid mental and substance disorders among the elderly: conceptual issues and propositions. Behav Health Aging 1:163170.

Thun MJ, Peto R, Lopez AD, Monaco JH, Henley SJ, Health CW, Doll R (1997) Alcohol consumption and mortality among middle-aged and elderly US adults. N Engl J Med 337:1705-1714.
Turvey CL, Conwell Y, Jones MP, Phillips C, Simonsick E, Pearson JL, Wallace R (2002) Risk factors for late-life suicide: a prospective, community-based study. Am J Geriatr Psychiatry 10:398-406.

Vestal RE, McGuire EA, Tobin JD, Andres R, Norris AH, Mezey E (1977) Aging and ethanol metabolism. Clin Pharmacol Ther 21:343354.

Wallace P, Cutler S, Haines A (1988) Randomised controlled trial of general practitioner intervention in patients with excessive alcohol consumption. BMJ 297:663-668.

Waller SJ, Lyons JS, Costantini-Ferrando MF (1999) Impact of comorbid affective and alcohol use disorders on suicidal ideation and attempts. J Clin Psychol 55:585-595.

Wetle T (1997) Living longer, aging better: aging research comes of age. JAMA 278:1376-1377.

Williams GD, Debakey SF (1992) Changes in levels of alcohol consumption: United States, 1983 to 1988. Br J Addict 87:643-648. 